INDO GLOBAL JOURNAL OF

PHARMACEUTICAL SCIENCES

ISSN 2249- 1023

\title{
Comparison of Lipid Extraction Method for Chlorella sp. Using an Open Pond Reactor
}

\author{
Shruti Ahuja, Tushita Attre, Navneeta Bharadvaja * \\ Plant Biotechnology Laboratory, Department of Biotechnology, Delhi Technological University, Delhi-110042, India \\ Address for Correspondance: Navneeta Bharadvaja, shruti.m.ahuja@gmail.com; navneetab@dtu.co.in ; tushita.attre@gmail.com
}

\section{Keywords}

Chlorella sp.;

Solvent Extraction;

Wet Lipid

Extraction; Dry Lipid Extraction; Milking; FAME Analysis .
ABSTRACT: World's crude oil reserves are decreasing with a continual increase in energy prices, this has led to an increasing interest in developing renewable alternatives to petroleum-based liquid fuels. An alternative that has received consideration is growth and harvest of microalgae for production of biodiesel via extraction of micro-algal oil or lipids. However, costs related to growth, harvesting, dewatering, and processing of algal biomass have limited the commercial scale production of biodiesel produced from algae. The following study thus focusses on finding an economical solution by comparing different ways of lipid extraction using 3 different set of solvents having low toxicity with respect to standard Bligh and Dyer method and different harvesting techniques for Chlorella $s p$. Cultures were procured from The Energy and Resource Institute, New Delhi. Experiments were initially performed in conical flasks using Bolds Basal Medium and were later transferred to an artificially created glass tank to recreate open tank reactor conditions. The flask cultures were occasionally shaken by hand and were maintained at $25^{\circ} \mathrm{C}$, at neutral $\mathrm{pH}$ and continuous 24 hours light conditions. Lipid extraction was performed using dry, wet and milking lipid extraction and the results were compared using FAME analysis. The costs of three lipid extraction method were calculated and evaluated. As per the results milking can be used as a commercial alternative to dry lipid extraction method. (c) 2016 iGlobal Research and Publishing Foundation. All rights reserved.

Conference Proceedings: International Conference on Advances in Plant and Microbial Biotechnology (PMB2017); JIIT, Noida: February 02-04, 2017

Indo Global Journal of Pharmaceutical Sciences( ISSN 22491023 ; CODEN- IGJPAI; NLM ID: 101610675) indexed and abstracted in EMBASE(Elsevier), SCIRUS(Elsevier),CABI, CAB Abstracts, Chemical Abstract Services(CAS), American Chemical Society(ACS), Index Copernicus, EBSCO, DOAJ, Google Scholar and many more. For further details, visit http://iglobaljournal.com 